\title{
Espacio y vitivinicultura. Marco territorial y apuntes tecnológicos de los vinos de licor
}

\author{
Francisco del Castillo Garcia
}

\section{INTRODUCCION}

Es por todos conocida la fuerte contracción que ha sufrido la demanda de vino en España en los últimos tiempos, sobre todo en los cinco años anteriores, estimándose en estos momentos un consumo en torno a 40 । por habitante y año. Dentro de este descenso generalizado el más perjudicado ha sido el mercado de graneles dada la tendencia a consumir mejores calidades. No obstante hay unos determinados vinos que están en una situación precaria y que al contrario de los graneles tienen una gran calidad y sobre todo una marcada personalidad, son los llamados vinos de licor. Éstos a pesar de su larga tradición y debido a diversas causas (moda, poca rentabilidad,..) son poco conocidos y casi siempre ignorados hasta incluso por los profesionales del sector vitivinícola.

Una vez hechas estas consideraciones previas, se desea con este apartado introductorio, simplemente resaltar la intención del articulo, que pretende en primer lugar hacer hincapié en la decisiva relación que existe entre el medio geográfico y estos vinos de caracteristicas tan singulares. indudablemente lo primero que se debe hacer es tratar de explicar brevemente qué son los vinos de licor, y para ello se ha dedicado un apartado conceptual, que puede resultar árido y quizás hasta farragoso, pero que es absolutamente necesario para rentabilizar mejor la posterior lectura. Después se estudiarán las citadas relaciones de los vinos de licor con el medio geográfico, un medio que comprende tanto factores físicos como humanos. Lógicamente, debido al aspecto sintético del estudio, se van a esbozar sólo los elementos más relevantes de los citados factores haciendo también referencia a las prácticas enológicas más significativas. En definitiva, que se realizarán unos breves apuntes tecnológicos de los 
vinos de licor en España, después de hacer una «telegráfica» pero necesaria contextualización europea. Se finaliza el estudio con unas reflexiones de marcado carácter vindicativo sobre el presente y el futuro de estos vinos que tienen mucha personalidad pero que son escasamente demandados.

\section{CONCEPTO DE VINO DE LICOR}

No es tarea fácil exponer en pocas líneas las distintas concepciones que existen sobre estos vinos y más aún cuando se quiere abarcar un ámbito mayor del que la propia definición contempla, por lo tanto, cuando en este trabajo se hable de vinos de licor se hará referencia a los llamados vinos de postre, vinos dulces naturales, generosos y vinos de licor propiamente dichos. Como existen notables diferencias entre los distintos países el artículo se va a basar en la reglamentación española y algo en la comunitaria, porque no se quiere abusar de los aspectos legales.

En España es una importante fuente la famosa Ley 25/70 el «Estatuto de la viña, del vino y de los alcoholes» que señala:

En su artículo 15,

"Se denominan "vinos dulces naturales" a los que por proceder de mostos de alta riqueza en azúcares, superior a 272 gramos por litro, fermentan parcialmente. Su graduación alcohólica deberá ser, como mínimo de ocho grados.

Los vinos dulces naturales dedicados directamente al consumo tendrán una graduación alcohólica adquirida máxima de $18^{\circ}$, que puede ser alcanzada por la adición de alcohol de vino exclusivamente».

En el Art. 17.1,

" "Vinos generosos" son los vinos secos abocados o dulces producidos por variedades selectas de uva, que siguiendo normas tradicionales o particulares (incluidas la adición de alcohol de vinos en determinadas fases de su elaboración y la de vinos dulces naturales), les dan características distintivas y cuya graduación alcohólica está comprendida entre 14 y 23 grados. La mayor parte de su grado alcohólico deberá proceder de la fermentación del mosto inicial".

Y por fin el Art.18, 
"Se denominan vinos licorosos los elaborados a partir de uva de variedades adecuadas, con la adición de alcohol vínico autorizado, vinos dulces naturales o de mostos y mistelas; su graduación alcohólica estará comprendida entre 13,5 y 23 grados, y su contenido en materias reductoras será superior a 50 gramos por litro, debiendo proceder la mayor parte de su grado alcohólico de la fermentación del mosto inicial”.

El Estatuto rizando el rizo, explica también los vinos licorosos generosos, cuando no ha explicado demasiado bien lo que es un generoso, ya que lo diferencia de los licorosos por el aporte de la tradición, y sin embargo la mayoria de los vinos de licor siguen procedimientos tradicionales.

No obstante lo señalado, la legislación comunitaria, más pragmática aclara en el Reglamento $4252 / 88$ algo más las cosas para los no introducidos en la enología, y en concreta referencia a los vlcprd (vinos licorosos de calidad producidos en región determinada) españoles establece en el apartado 1 de su Art. 14 lo siguiente:

"La mención especifica tradicional "vino generoso", solo podrá utilizarse para el "vlcprd" seco elaborado bajo velo y:

- que se obtenga a partir de uva blanca procedente de las variedades de vid Palomino de Jerez, Palomino fino, Pedro Ximénez, Verdejo, Zalema y Garrido fino,

- que se despache al consumo tras un periodo medio de crianza de dos años en toneles de roble».

Serán por tanto generosos algunos de los incomparables y famosos vinos de Andalucia Occidental y de Rueda, es decir, los finos, manzanillas, amontillados, pálidos, etc.

\section{MARCO DE REFERENCIA}

Las pautas de localización industrial de determinados tipos de empresas han ido cambiando de forma vertiginosa en los últimos tiempos, con los conocidos fenómenos de descentralización favorecida por la segmentación de los procesos productivos. Aunque no existen demasiados estudios es un hecho contrastado que la tendencia en la localización del sector agroalimentario (tan tradicionalmente apegado al medio rural) está también variando acercándose, en la medida que le permite su valor añadido, cada vez más a los mercados de consumo. 
Pero estos fenómenos no son válidos para el sector vitivinicola, en el cual y debido a la peculiaridad del producto elaborado existe una inseparable vinculación de la bodega con la viña que es absolutamente necesaria. En efecto, la moderna enología más que aconsejar casi impone una cierta cercania entre el viñedo y la bodega. Al margen de las causas legales de los vinos de calidad, que ya tienen per se una decisiva importancia (D.O., etc.), si para conseguir un buen vino se necesita partir de una uva en buen estado, es evidente que cuanto menos dure su transporte menor será también el riesgo de oxidaciones y fermentaciones indeseadas.

Siendo el vino el producto agrícola más sensible al medio físico, paradójicamente, es también en el que tiene una mayor incidencia el hombre, y por lo tanto es lógico que haya sido el primer producto que se ha beneficiado del concepto de Denominación de Origen, idea que enlaza de forma perfecta la vitivinicultura con la Geografía, entendida ésta en un sentido más amplio que el mero medio físico, es decir, considerando también el decisivo aporte humano.

Sirva como iniciación a este concepto el artículo 2 del Acuerdo de Lisboa sobre protección de Denominaciones de Origen de 31 de octubre de 1958 que establece:

«Se entiende por denominación de origen, en el sentido del presente Acuerdo, la denominación geográfica de un pais, de una región o de una localidad que sirve para designar un producto que es de alli originario y cuya calidad y caracteres son debidos exclusivamente o esenciaimente al medio geográfico comprendiendo los factores naturales y los factores humanos.

El pais de origen es en el cual está situada la región o la localidad cuyo nombre constituye la denominación de origen que ha dado al producto su fama».

Parece lógico suponer que debido a la mayor intervención del hombre en el proceso de elaboración de los vinos de licor deberian ser éstos más independientes del territorio, pero nada más lejos de la realidad, ya que sólo se pueden elaborar en algunas zonas vitivinicolas. Por lo tanto, si existe una fuerte relación entre el medio geográfico y la vitivinicultura en general, en el caso de los vinos de licor, como se podrá apreciar más adelante, el vínculo se refuerza de forma extraordinaria.

Una prueba evidente son las abundantes Denominaciones de Origen (en adelante D.O.) que exclusivamente contemplan la elaboración de estos vinos, número que se amplia considerablemente con aquellas que 
Espacio y vitivinicultura. Marco territorial y apuntes tecnológicos ...

también amparan otro tipo de vinificaciones. Como ejemplo se citan a continuación algunas de ellas.

En el primer apartado podemos encontrar: V.D.N. (Vins Doux Naturels) como Banyuls, Maury, Muscat de Frontignan, etc.; Oportos; Moscatel de Samos, de Creta; Marsala; Madeira; Jerez, Montilla-Moriles; Málaga; etc.

En el segundo: Alicante; Rueda; Priorato; Tarragona; Pineau de Charentes; etc.

\section{MEDIO FISICO Y VINOS DE LICOR}

Dentro de los múltiples factores que influyen en cualquier viñedo y más aún en los dedicados a la elaboración de vinos de licor, sobresalen por su importancia el suelo, el clima, la microflora, y en estrecha relación con los dos primeros la configuración del terreno. Se van a tratar con brevedad todos excepto la microflora debido a que requeriria un estudio más especifico y de otras características. Sin embargo, en los vinos de crianza biológica será inevitable referirse al fundamental y no siempre valorado trabajo de las levaduras que en este caso tiene una importancia decisiva.

El suelo.-Es un factor al que no se le suele dar la importancia que merece, $y$ todo porque normalmente se toma como soporte en el cual se puede lograr por la acción del hombre (fertilización, abonado, etc.) la composición de nutrientes que se desee. Sin embargo también importa y mucho su estructura física, es decir su textura y profundidad. «El suelo no solo es el soporte físico de la planta sino que debe tener la textura y la composición adecuadas que permitan al sistema radicular de la planta disponer del agua y de los aportes minerales que son indispensables para el desarrollo normal del ciclo vegetativo y de los procesos de fotosintesis" (Yravedra, G. 1983).

Como hay una estrecha relación entre el suelo y el microclima dentro del biosistema de cada zona geográfica, habrá que intentar localizar el viñedo no en suelos profundos (en los cuales se consiguen grandes producciones en detrimento de la calidad) sino en aquellos que tengan la suficiente humedad que permita la incorporación a la planta de los nutrientes que precisa en función de la variedad de vid que se trate y del vino de licor que se pretenda conseguir. No obstante en paises de vitivinicultura más joven como Chile, Argentina, Sudáfrica, Australia, etc., son frecuentes los viñedos en suelos de aluvión de gran fertilidad, aunque también hay que decir que sus vinos de licor (que en muchos casos son 
burdas imitaciones) no alcanzan las cotas de calidad de los países con más tradición. En éstos (España, Portugal, Francia, Italia, etc.), gran parte de los viñedos se establecen en suelos muy pobres, sin apenas materia orgánica y con poca reserva hídrica, lo que conlleva, lógicamente, poco vigor de la planta pero por el contrario una gran riqueza en azúcares en las bayas.

Debido a la enorme diversidad de este tipo de elaboraciones, y a su gran dispersión por todo el mundo los suelos donde se localicen los viñedos serán, por lo tanto, muy variados, baste señalar entre otros ; calcáreos y arenosos (Jerez, Montilla-Moriles,..), calcáreo-arcillosos (Marsala), esquistosos (numerosos V.D.N.), esquistosos en terrazas (Oportos), en roquedo de génesis volcánica (Madeira, Lanzarote, La Palma, Santorín, ..) por citar algunos ejemplos de famosos vinos de licor de paises europeos.

Sin embargo, y dentro de suelos de una cierta pobreza parece existir una preponderancia de dos tipos, los calcáreos y los esquistosos. "En efecto, los vinos de licor tintos más afamados Banyuls, Maury, Oporto "han nacido" de viñedos establecidos sobre esquistos..." (TorRES, P. 1991).

El ámbito de los suelos calizos es mayor, encontrándose en España en proporciones estimables en Alicante, Terra Alta, Málaga, Valencia, etc. en el caso de Jerez y Montilla-Moriles por su particular importancia se estudiará la incidencia de sus albarizas y alberos más adelante. Es interesante la observación que hace el experto francés en este tipo de vinos $P$. Torres sobre la fuerte vinculación entre los viñedos de moscatel más afamados en la producción de vinos de licor y los suelos calcáreos, señalando entre ellos: Moscatel de Frontignan, Mireval, Setúbal, Samos, Pajarete (elaborado en Chile con gran proporción de moscatel), etc.

El clima.-Aunque hay algunas excepciones que confirman la regla, los vinos de postre se suelen dar en dominios climáticos en los que "se constata que la suma de temperaturas activas $(<\mathrm{Ta}=$ suma de las diferencias entre la temperatura diaria y $10^{\circ} \mathrm{C}$ ) es la mayor parte del tiempo superior a 1500" (TORRES, P. 1991).

Dentro de estos dominios climáticos se pueden citar ejemplos bastante conocidos... «es el caso de los viñedos de España (2.700 en Jerez, 2.100 en Tarragona, 1.800 en Valencia), de Sicilia y de los viñedos del Sur de Italia, de los viñedos de la región de Mendoza en Argentina, o del Norte de Chile (2.000 a 2.500), de Australia (1.800 a 2.200) o de Israel (2.300 a 2.700). La zona de los V.D.N. franceses (Banyuls, Rivesaltes,..) varia entre 1.900 y 2.000 " (TORRES, P. 1991). No hay que insistir más en este aspecto, es sobradamente conocido que un viñedo con pocas precipitaciones y alta 
insolación proporcionará una materia prima ideal para los vinos de licor, es decir una uva con una elevada riqueza en azúcares.

También es fundamental el clima, pero incidiendo de otra forma, en la elaboración de los famosos y costosos vinos de Sauternes, Tokay, Auslëse, etc. En este caso, como ya se sabe, las bayas se van a pasificar por medio de la acción de un hongo, la Botrytis cinerea, lo que requiere unas especiales situaciones de humedad y temperatura en todo el largo proceso de recolección (exige efectuar varias pasadas de vendimia para recoger la uva en el momento óptimo de pasificación). Más adelante se profundizará en estas míticas e interesantísimas elaboraciones.

Por lo tanto el clima va a ser un factor determinante en la elaboración de los vinos de licor, y hasta tal punto es asi, que en ciertos paises del centronorte de Europa se decia hace algunos años que «...existen ciertos tipos de vino que se obtienen sin fermentación y que presentan un alto grado alcohólico y generalmente también notable graduación glucométrica... son los llamados vinos de postre, también conocidos por vinos del Sur y vinos dulces, según la Ley Vinicola Alemana" (VOGT, E. 1971).

Además de los ya citados hay otros elementos climáticos que tienen notable incidencia, como la afinidad de bastantes viñedos con el litoral. Es altamente significativa la marcada vocación costera que tienen muchos vinos de licor (Jerez-Manzanilla, Samos, Pantellería, Sicilia, etc.), y ello se debe a la necesaria y en ocasiones imprescindible acción de la brisa del mar, o mejor dicho de una cierta humedad relativa del aire, ya sea para compensar las carencias hidricas del estio, o porque resulte esencial para el proceso de elaboración como ocurre en Jerez-Manzanilla (para permitir la acción de las levaduras filmógenas).

En otros casos determina diferentes calidades, "en el caso de la producción del Marsala es la región costera la que, beneficiándose de un efecto suavizante, obtiene los mejores resultados» (ToRRES, P. 1991).

Otro aspecto que no se debe olvidar es la altitud orográfica de la zona del viñedo, que, o bien determina en algunos casos umbrales de viabilidad para la obtención de estos vinos (Rousillon en los V.D.N.), o en otros, una diferenciación cualitativa de los mismos, tan evidente, que se contempla en los reglamentos (Montilla-Moriles, Oporto, Peloponeso, etc.).

La configuración del terreno.-Por último para finalizar con los factores físicos solo reseñar la importancia que la configuración del terreno (factor como es sabido vinculado al suelo y en relación con el clima) tiene para todos los vinos.

Son siempre preferibles las vertientes o colinas porque permiten una mejor aireación de la planta y favorecen el drenaje. Por ese motivo abun- 
dan las viñas situadas en laderas, que a veces son tan escarpadas que precisan, como en el caso de Oporto, de Madeira, etc., la preparación o formación de bancales o terrazas. «La vertiente o la colina presenta dos aspectos muy favorables: la posibilidad de elegir una inclinación que permita obtener la insolación que mejor conviene y la facilidad del drenaje que procurará a la planta un suelo perfectamente saludable. Sobre la vertiente, se tendrá rendimientos inferiores pero las graduaciones glucométricas serán más elevadas y el grado de maduración más apropiado, aspectos que son muy positivos en cuanto a la calidad del vino" (YravedRA, G. 1983). Ni que decir tiene que estos citados aspectos cobran aún una mayor relevancia en el caso de los vinos de licor.

\section{FACTORES HUMANOS EN EL VIÑEDO DE LOS VINOS DE LICOR}

La acción del hombre es fundamental no solo en la bodega sino también en el viñedo, aspecto importante, y al que a veces no se le otorga el protagonismo que merece. En este sentido se van a señalar como generalización (más adelante se profundizará al tratar los vinos) sólo algunos puntos de interés que sirvan para centrar el tema de estudio, y entre ellos destacan las variedades de vid, el portainjerto, y las prácticas culturales de las cuales se va a realizar un breve esbozo.

Dentro de la responsabilidad del hombre la primera cuestión que hay que afrontar es la variedad de uva y el portainjerto, elementos que están insertos en el ya referido medio físico. Existe una enorme variedad de cepas para vinos de licor, y pueden ser tanto blancas como tintas, y autóctonas (específicas de una región) o ubicuas (muy repartidas). Dentro de las especificas destacan las que sirven de base para los excelentes Oportos (Rabigato, Donzelinho, Touriga, Mourisco, Tinta Amarela, etc.), la Mavodaphne de Grecia, la Grillo de Italia, etc. Las repartidas son muy numerosas como las Malvasia, Garnacha, Pedro Ximénez, Macabeo, Syrad, Cariñena,..., y las Moscateles, tanto la de Alejandría como la de grano pequeño. La de Alejandria es la más ubicua de todas, se extiende por todo el mundo y normalmente recibe "el apellido" de la zona en la que se cultiva, de Málaga, de Setúbal,..). «Es una cepa tardía que por exigir mucho calor se explica su implantación en los dominios climáticos particularmente cálidos" (ToRres, P. 1991). La Moscatel de grano pequeño se suele cultivar en las A.O.C. de los V.D.N. (muscat de Frontignan, de Mireval, ..), en Grecia (de Samos), en Australia, Sudáfrica, etc.

El portainjerto es una planta con raices muy resistentes al ataque de la filoxera, y su elección es de capital importancia ya que debe tener una 
completa afinidad con la variedad que se injerta para obtener la clase de uva que se desea. Hay que recordar que el portainjerto, también llamado patrón, será el encargado de absorber los nutrientes para la parte aérea de la planta, que aprovechando el aporte de savia, será la responsable de «fabricar» la cosecha por medio de la fotosintesis utilizando la luz, el calor y también la humedad del aire.

Las prácticas culturales tienen también un marcado protagonismo, e influyen en la calidad de la uva, las principales son la densidad de plantación, el mantenimiento de suelo (laboreo, herbicidas, etc.), los distintos sistemas de conducción y poda, la fertilización, el riego, etc.

\section{LOS VINOS DE LICOR EUROPEOS}

Aunque se carece de las suficientes pruebas, parece ser que el origen de estos vinos en el continente europeo se remonta a periodos tan remotos como la Grecia clásica y Roma. No obstante, se quiere apuntar una aventurada hipótesis de su presunta génesis en los párrafos siguientes.

Virgilio que era uno de los escritores romanos que mejor conocian el mundo del vino, señaló que en su tiempo los tipos de vid eran «tan numerosos como los granos de la arena del desierto", sin embargo, no todas se debian cultivar para vinificación, ya que otros autores afirman que los vinos de griegos y romanos se elaboraban con variedades como moscateles, malvasias, etc. Si partimos del último supuesto y dado el cálido clima de estas regiones es fácil suponer que el contenido en azúcares de estas aromáticas uvas tendria que ser necesariamente alto. $Y$ este alto contenido puede que fuera el responsable en algún caso, de la falta de respuesta de las levaduras, es decir, de fermentaciones incompletas, que diesen lugar, de forma accidental, a una bebida de baja graduación alcohólica, elevado dulzor y potentes aromas.

Por otra parte, y dado el escaso conocimiento enológico de la época, era una práctica habitual añadir aguardiente a aquellos vinos que no se habian consumido (a los pocos meses de su elaboración), para conservarlos mayor tiempo. Por lo tanto, es razonable sospechar, que los vinos de licor puede que nacieran de forma accidental (fruto de la casualidad), o que su origen se deba a necesidades de conservación. Si fuese por esta última causa tendrian un notable paralelismo con los salazones, escabeches, etc. alimentos, que, a pesar de haber sido solucionados, por los 
avances de la tecnologia, los problemas que hicieron posible su existencia, se han mantenido en el tiempo gracias a su calidad y originalidad.

En contraste con la época actual, es indispensable resaltar que los vinos de licor tuvieron su momento de máximo esplendor desde el siglo de las luces hasta finales del xIx, e incluso en ese periodo de tiempo eran los vinos más importantes (Oporto, Jerez, Tokay, Madeira, y los mediterráneos Marsala, Málaga, etc.). Pero que nadie se asuste, que no se pretende hacer un estudio histórico de estos vinos aunque sí una contextualización europea que sirva de referente antes de entrar en los españoles.

Se van a señalar algunos de los vinos de licor que pudieran tener un mayor interés. Es conocido que los humanos tienen (tenemos) un desmedido afán taxonómico, o en el mejor de los casos la «mania» de etiquetar o clasificar cualquier universo que se estudia. En este caso, no debe extrañar que como en cualquier conjunto complejo de elementos, existan tantas clasificaciones como clasificadores, algunas de ellas muy sencillas como la implicita separación que Ribereau-Gayon y Peynaud (1976) hacen en su tratado de enologia (“dulces naturales» y «espirituosos»), y otras, muy complejas, como la que presenta Tulio de Rosa (1987) en su tecnología de vinos licorosos y de postre (considera múltiples aspectos como su sabor, origen, elaboración, etc.).

En este caso y por cuestiones de sencillez se va a realizar la única distinción entre vinos que parten de uvas pasificadas por efecto de la podredumbre noble y los que no han sufrido el ataque del hongo.

En el primer caso existen numerosos casos en Europa (en España ninguno), entre los que destacan los Sauternes y Barsac, Tokay, Auslese del Rhin, Orvietano, etc.

Aunque existen zonas de importancia como el Jura («vins jaunes»), Tirol, Rheingau (Spätlese), etc., en los restantes vinos de licor hay una marcada «dominancia mediterránea» o al menos meridional, Marsala, Málaga, Nasco, Reciotos, Mónica di Cagliari, della Commandaria, Maphrodaphone, Oporto, Madeira, Jerez, Montilla, Fondillones, etc., y diversos Moscateles (de Samos, de Asti, de Siracusa, de Frontignan, de Setúbal, de Valencia,..) y Malvasias (de Bosa, de Lipari, de Sitjes, de Lanzarote,...). Quizás por este motivo no vaya tan descaminada la ya citada legislación alemana en su consideración de vinos de postre como vinos del sur.

Vinos de Sauternes-Barsac, Tokay y Auslese.- Estos vinos son tan singulares que, como ya se ha adelantado en la parte dedicada al medio físico, solo se dan en algunas regiones con peculiares condiciones climáticas (otoños benignos con abundantes neblinas) que favorezcan el ataque de la botrytis cinerea a determinadas variedades resistentes a este hongo. 
En contra de lo que se piensa estos vinos son relativamente baratos y poco rentables, «el factor riesgo es impresionante, ya que el mal tiempo en octubre puede arrebatarle al agricultor la posibilidad de obtener vino dulce, y en algunos casos, de lograr simplemente vino" (JOHNSON, H. 1979). Sin embargo algunos de ellos se encuentran entre los vinos más caros del mundo como los Château d'Yquem (Premier Gran Cru) del Haute Sauternes, y este elevado precio se justifica por diversas razones. Entre ellas destacan; la producción escasa de la variedad Semillon (acentuada por una poda fuerte), el elevado coste que supone seleccionar las uvas en el momento exacto de podredumbre (lo que exige realizar varias pasadas de vendimia) y, obviamente, el bajo rendimiento de las uvas seleccionadas.

En efecto, como señala De Rosa (1987) la pasificación producida por el hongo causa una disminución cuantitativa de hasta un 50 por 100. Pero como contrapartida, «el resultado es un vino con una intensidad de gusto y aroma y una textura tan suave y casi oleosa que, en el supuesto caso de lograrse, muy difícilmente se podría obtener de otra manera» (JOHNSON, H. 1979).

Dentro de las singulares características de estos vinos se pueden destacar una graduación alcohólica de 13 a $15^{\circ}$, una acidez que oscila entre los 5-9 g/l y un contenido en azúcares bastante elevado (6-15 por 100). Para mayor información pueden utilizarse los estudios de Ribereau-Gayon y Peynaud (1976) y De Rosa (1987).

El procedimiento de elaboración es similar, aunque las variedades de uva son diferentes, Semillón (Sauternes), Furminto (Tokay) y Riesling (Berenauslese), las fermentaciones son muy lentas, las levaduras trabajan con dificultad y son altas las proporciones de azúcares residuales de los vinos terminados. La podredumbre según los estudios de Pucheu-Plante et al. (1978), se desarrolla sobre granos de uva intactos, que alcanzada la madurez se dejan en la cepa un tiempo para obtener una adecuada sobremaduración. Una vez que el hongo ha afectado los hollejos, comienza su desarrollo de forma progresiva y variable, de tal forma que en un mismo racimo la alteración no es homogénea.

«De hecho se pueden ver:

- Granos verdes, intactos, maduros, no parasitados y de piel dorada.

- Granos con podredumbre "plena", de piel oscura y lisa, cuyo hollejo se encuentra parasitado interiormente por el hongo.

- Granos "rôtis" o "almibarados", marchitos y arrugados, con aspecto de uva pasa, pero con pequeños mechones grises de conidióforos que recubren el hollejo. 
Sólamente estos últimos son apropiados para elaborar un buen Sauternes» (SUÁREZ, J.A. e ÍṄIGo, B. 1990).

Para más información tanto biológica como bioquímica, véase Microbiología Enológica de los anteriores autores, los cuales en base a los estudios realizados en la zona de Burdeos por Pucheu-Plante ofrecen una clara síntesis de enorme interés.

Los vinos de Sauternes tienen, lógicamente, una estricta reglamentación, y deben tener una graduación alcohólica superior a los $13^{\circ}$, estando prohibida la adición de alcohol y de azúcar o mosto concentrado al mosto base.

Los vinos de Tokay son los más famosos de Hungría y se producen al nordeste del país al lado de la frontera con la U.R.S.S. Se elaboran fundamentalmente con la variedad Furminto, en menor proporción la Lindenblättriger y de forma minoritaria el Moscatel amarillo. Son muy apreciados desde la época de Luis XIV, y existen varios tipos siendo el Aszú, de selección, (similar al alemán Trockenbeerenauslese) el de mayor calidad.

Para elaborar el Aszú se utiliza una proporción de racimos afectados por el hongo, que se expresa en "putts» especie de envases en los cuales se contiene la pulpa de las uvas «botrytizadas" que se añadirá a la "vendimia sana». De esta forma las calidades vienen determinadas por el número de putts, dato que debe figurar en la etiqueta. La de máxima calidad se tiene en el Aszú Eszencia para el cual se emplea casi en exclusiva la uva atacada, este vino de lujo, es hoy un esplendoroso vestigio del pasado. Sin embargo, cuando la añada es excepcional, a veces se elabora, y siempre con prolongada crianza. «El Aszú Eszencia envejece en botella por un tiempo minimo de 20 años y su precio es casi 20 veces superior al de un buen Aszú» (DE RosA, T. 1987).

El Rheingau es la región alemana con mayor cantidad de uva Riesling, $y$ en donde se producen, cuando las condiciones meteorológicas lo permiten, los famosos Auslese, aunque algunos autores consideran a los Auslese los vinos obtenidos a partir de uvas sobremaduras con selección de racimos.

Estos vinos tienen diferentes categorias «Berenauslese» cuando las uvas atacadas por la Botrytis son recogidas grano a grano y "Trockenberenauslese" cuando las uvas botrytizadas son recogidas muy arrugadas y casi pasificadas. Los "auslese» participan de similares caracteristicas que los Sauternes y Tokay, y están ubicados desde el punto de vista de la legislación alemana en la máxima categoria, similar a los AOC franceses, DOCG italianos, etc., los cotizados QmP (vino de calidad superior con características especiales). 
Vinos de licor de la Europa Meridional.-A pesar de las enormes calidades de estos vinos, este apartado si pretende ser breve para no amplificar demasiado el estudio. No obstante la, quizás, excesiva extensión dedicada a los Sauternes, etc., está justificada, más que por su innegable singularidad, por ser un tipo de vino que no se elabora en ninguna región española. Por este motivo, solo van a reseñarse los Oportos, Madeiras, Marsalas y Moscateles.

Los vinos de Oporto, ¿Cómo empezar con unos vinos tan acreditados y famosos?, y que, posiblemente sean junto con los de Jerez los vinos más prestigiosos del mundo. En primer lugar, no estaria de más señalar, aunque sobra el comentario, por conocido, que se elabora en la zona del Alto Duero, en la "Regiâo Demarcada dos Vinhos Generosos do Douro" que abarca $250.000 \mathrm{Ha}$ de los Distritos de Vila Real, Bragança, Vizeu y Guarda.

El vidueño se localiza normalmente en las inclinadas laderas (terrazas escalonadas) del valle. «El suelo esquistoso, el relieve atormentado, el clima caracterizado por contrastes térmicos estacionales acentuados, una débil pluviosidad, y una insolación intensa durante la evolución de la uva, crean condiciones muy especiales propias para la obtención de los vinos de Oporto" (RIBereau-Gayon et alii, 1976).

Las variedades de uva son tan numerosas como poco conocidas, y como el Oporto es un vino en el que el "coupage» tiene gran importancia, se podría decir que de esta forma se empieza a realizar ya en el vidueño. «Entre las uvas de uso más generalizado en los valles del Duero se cuentan entre las tintas: Malvasia preta, Mourisco tinto, Tinta amarela, Tinta barroca, Tinto Câo, Tinta Ririz, Touriga francesa, Touriga nacional. Entre las blancas son preferentes: Codega, Gouveiro, Malvasia fina, Malvasia Rei y Rabigato" (MARTINEZ LLOPIS, M. 1988).

El proceso de elaboración es, en sintesis: se realiza una vinificación con uvas sin despalillar, estrujadas y puestas a fermentar, poniendo especial énfasis en el logro de la máxima extracción de antocianos y polifenoles, para obtener el color adecuado y la necesaria protección que precisa su prolongado envejecimiento (PeYnaud, E. 1989; dE Rosa, T. 1987, etc.). Después de obtenido el grado alcohólico deseado, que depende del tipo de vino que se quiere elaborar, se añade aguardiente de $77-78^{\circ}$ para detener la fermentación. En este caso conviene resaltar, como señala De Rosa (1987), que el vino seco alcanza la graduación alcohólica natural de 12 , mientras que en el dulce se detiene la fermentación cuando el vino presenta una densidad de $6-7^{\circ}$ Beaumé.

Si por algo se distinguen los Oportos es por su, ya citado, largo envejecimiento, “los mejores obtienen su precinto de verificación del insti- 
tuto estatal sólo al cabo de un almacenamiento de 7 años, en cuba" (BıBuLus 1986). Y esta conservación, siguiendo a Peynaud, se efectúa en pipas (sin llenar) de 550 litros, y el envejecimiento dura para los vinos más jóvenes de cuatro a cinco años.

La calidad constante se logra por medio de mezclas, pero «las añadas de gran calidad permiten embotellar, después de dos años de conservación en barriles atestados, de tipo "vintage», cuya crianza se hace protegida del aire y muy parecida a la empleada en la crianza normal de los vinos tintos finos» (PEYNaud, E. 1989).

Sus características compositivas son diversas dada la enorme variedad de los Oportos, pero se podrian apuntar algunos «parámetros similares» que señala De Rosa para los tintos: graduación alcohólica en torno a los 20 , cenizas $2 \mathrm{~g} / \mathrm{l}$, acidez total (en tartárico) de $4,5 \mathrm{~g} / \mathrm{l}$, extracto seco $22 \mathrm{~g} / \mathrm{l}$ y un contenido en SO2 total de $22 \mathrm{mg} / \mathrm{l}$.

Otra peculiaridad desde el punto de vista organoléptico, es la prolongadísima persistencia que de esta manera se convierte en una de sus mejores «armas» frente a los fraudulentos imitadores. En algunos Oportos excepcionales se ha alcanzado una persistencia de casi ¡10 minutos!,....sobra cualquier comentario.

Como hay muchos tipos de Oporto, se prestan a múltiples clasificaciones de diferente naturaleza, pero aquí, solo se va a citar una, la que considera el contenido en azúcares, y que determina que estos vinos sean: Extra Seco $\left(0^{\circ} \mathrm{Bé}\right)$, Seco $\left(0-1,5^{\circ} \mathrm{Bé}\right)$, Meio Seco $\left(1,6-3^{\circ}\right.$ Bé), Doce $\left(3,1-5^{\circ}\right.$ Bé) y Muito Doce o Lagrima $\left(5,1-7^{\circ} \mathrm{Bé}\right)$.

Para terminar, puede ser interesante añadir alguna referencia a los distintos tipos que se elaboran. Hay vinos blancos y tintos, pero los primeros pueden ser secos o dulces y los tintos sólo son dulces. Además desde el punto de vista cualitativo, son normales o especiales. En estos últimos se deben reseñar en la etiqueta y de mayor a menor calidad las denominaciones "vintage", "Late Bottled Vintage", "cosecha" y "edad". Los normales varian desde los jóvenes "Full» (de intenso color y afrutados), hasta los raros y excelentes "Crusted" ("casi» de la calidad de los de añada) pasando por los Ruby (más viejos y menos agresivos que los Full, pero que no mejoran en botella) y los Tawny (de color «bronceadogranate", con una crianza de ocho años, pero también sin mejorar en botella).

En la bella isla de Madeira, portuguesa, aunque geográficamente africana (a unos $650 \mathrm{~km}$ de la costa marroqui) y con un clima poco propicio (por la poca variabilidad estacional, $32^{\circ} 41^{\prime} \mathrm{N}$ ) para los vinos normales se elabora uno de los vinos licorosos más famosos del mundo. Parece ser 
que su origen es accidental, y de similares características (por lo menos en lo referente al transporte), al del amontillado jerezano, y de ser así, se podria aplicar igual que en el caso del excelente vino andaluz, el famoso dicho de "no hay mal que por bien no venga".

La materia prima se obtiene sobre todo de variedades blancas, como Malvasia, Verdelho, Sercial y Bual, y de la tinta Negramoll. Los vinos son, como ahora se dice, monovarietales, y por lo tanto presentan sustanciosas diferencias.

Como rasgos caracteristicos merecen destacarse, siguiendo a De Rosa, un mínimo legal de crianza de tres años, alto contenido en acetaldehido, notables dosis de acético que en los muy viejos puede llegar a valores del 0,2-0,25 por 100, pero imperceptibles en la cata. La concentración por deshidratación también hace subir la acidez total hasta valores en torno al 0,8-1 por 100 .

Los Malvasias (Malmsey o Sweet) son de color dorado con ambarinos tonos marrones, tienen aromas frutales y de uva pasificada y un sabor dulce de fruta madura y miel, acidez equilibrada y muy maderizados.

El Sercial (Seco reserva), es de color oro, bouquet en el que destacan la madera y el alcohol, y tonos de canela, seco con buena acidez (la volátil un poco alta) y claramente maderizado. Se debe tomar frio.

El Verdelho (Medium-dry), de color dorado ámbar con reflejos granates, con fuerte olor a madera, sabor moderadamente dulce con buena acidez y fuerte maderización. El Boal (Half-Sweet) es de color ambarino oscuro, con perfumes de uvas pasas, vainilla, madera y alcohol. El sabor es semidulce, uvas pasas, madera, se nota el alcohol y buena acidez.

Como explica De Rosa (1987) la fermentación alcohólica es rápida (se realiza a unos $30^{\circ}$ ), y una vez obtenido un vino con los azúcares residuales que se desean, se encabeza (con alcohol de 95-96.) hasta alcanzar una graduación aproximada de $17^{\circ}$. La posterior, y leve, adición de alcohol se suele realizar en el momento de la venta del producto, y con los $18^{\circ}$ se llegará debido a la pérdida de agua por evaporación a niveles incluso de $21^{\circ}$.

Una vez clarificado el vino tiene dos posibilidades de evolución, dos lineas diferentes de “maderización». La natural es compleja, laboriosa y con fuertes oxidaciones y la artificial consiste, en sintesis, en calentar a temperaturas de $45^{\circ} \mathrm{C}$ durante 2 ó 3 meses el vino por medio de unos serpentines de agua.

A pesar de no ser precisamente baratos, tanto los Madeiras secos como los dulces han sido muy utilizados, debido a su notable calidad, desde hace mucho tiempo por la alta cocina. 
Los Marsala se producen en el Noroeste de la isla de Sicilia, estando acogidos a D.O.C. e igual que en los casos de Oporto, Jerez y Madeira han jugado los ingleses un importante papel en su comercialización y difusión.

Las principales variedades utilizadas son las blancas Grillo y Catarrato, aunque también intervienen tintas como Pignatello, Calabrese y $\mathrm{Ne}$ rello. La elaboración del vino a partir de las uvas blancas se realiza cen blanco" y en el caso de las tintas se realiza una maceración normal no debiendo tener menos de $12^{\circ}$ de graduación alcohólica. De Rosa (1987), señala que un buen vino base debe tener entre otros los siguientes datos analiticos: Alcohol (13,8 por $100 \mathrm{vol}), \mathrm{pH}(3,43)$, acidez total $(5,6 \mathrm{~g} / \mathrm{l})$, SO2 total $(56 \mathrm{mg} / \mathrm{l})$, azúcares residuales $(1,3 \mathrm{~g} / \mathrm{l})$, extracto seco $(24,2 \mathrm{~g} / \mathrm{l}), \ldots$, etc. Posteriormente se le añade alcohol y mosto concentrado (39-40 Bé), una mistela (sifone), o mosto cocido, además al vino se le hace una pasterización $\left(75-80^{\circ} \mathrm{C}\right.$ cerca de 3 minutos), y los normales tratamientos de estabilización, etc.

Como en muchos vinos de licor, hay diversos tipos, según el color: oro, ámbar y rubi; según el contenido en azúcares: seco (menos de $40 \mathrm{~g} /$ I), semiseco (40-100 $\mathrm{g} / \mathrm{l})$ y dulce (superior a $100 \mathrm{~g} / \mathrm{l}$ ). Siguiendo con la tipologia, y con De Rosa (1987) se tienen los siguientes vinos: Marsala fine, Marsala superiore, Marsala superiore riserva, Marsala vergine y/o Soleras, Marsala vergine stravecchio y/o Soleras stravecchio. Además, también se hace vino aromatizado (Cremovo) a base de Marsala. Estos distintos vinos se hacen por mezclas del vino base, alcohol, sifone, mosto concentrado, mosto cocido, etc.

En las anteriores partes de este capítulo se han esbozado rasgos de vinos correspondientes a una zona geográfica concreta, pero en este aparte, se van a considerar de forma genérica los numerosos vinos de postre que, en el área mediterránea, y fuera de ella, se realizan a partir de una variedad tan aromática como la Moscatel.

Los Moscateles son muy abundantes, baste señalar entre otros los siguientes: de Pantelleria, de Montalcino, de Noto, de Trani, de Siracusa, Rosa, de Beaumes-de- Venise, de Lunel, de Mireval, de Frontignan, Aleatico, de Samos, de Setúbal, etc. en fin una larguisima lista que se aumentaría de forma considerable si se añadiesen los que se elaboran en España.

Resulta dificil extraer el factor común de elaboraciones de zonas tan distintas que normalmente tienen un marcado componente tradicional, y si se quiere hacer con rigor se entra en el terreno de la casuística, pero es necesario apuntar algunas ideas que permitan un mínimo acercamiento a estos vinos tan ubícuos. En la mayoria de las elaboraciones, se deja 
Espacio y vitivinicultura. Marco territorial y apuntes tecnológicos ...

sobremadurar la uva para que el mosto tenga una elevada concentración de hexosas y normalmente se suele parar la fermentación, con adición de alcohol, cuando quedan los azúcares residuales que se desean. No obstante, existen casos en los que el alcohol proviene exclusivamente de los azúcares de uvas, en avanzado estado de pasificación.

Algunos de estos vinos de Moscatel deben ser consumidos jóvenes y por el contrario otros, que suelen ser los más meridionales, tienen una larga vida, e incluso una dilatada crianza (más de tres años), normalmente en botella. Por su calidad merece destacarse en este último caso el Moscatel de Setúbal, excelente vino que tiene la peculiaridad de sufrir, una vez elaborado, una larga maceración con los hollejos de la uva (lo que le supone una extraordinaria ganancia en aromas) y un prolongado envejecimiento. Para algunos autores sólo se alcanza su óptimo de consumo después de 20 años, siendo en ese momento uno de los mejores vinos del mundo.

Para terminar este interminable capitulo, solo recordar que también existen en bastantes zonas europeas vinos de postre monovarietales (aunque no siempre al 100 por 100), de Malvasía, Garnacha, etc. Quizás los más importantes sean los primeros, que, a modo de curiosidad, tienen la sospechosa particularidad (seria interesante estudiar el tema) de elaborarse en la mayoría de los casos en terreno insular (Lípari, Etna, Rodas, Lanzarote, etc.).

\section{GEOGRAFIA Y TECNOLOGIA DE LOS VINOS DE LICOR ESPAÑOLES}

El título de este capitulo, ya anticipa un poco cómo se ha querido enfocar, desde el punto de vista formal, el estudio de los vinos de licor de España. En efecto, con fines meramente prácticos, se van a «encasillar» estos vinos en cuatro subconjuntos, tres de ellos corresponden a otras tantas zonas españolas y el restante de "otros vinos", es como un "cajón de sastre" adonde irán a parar los no encuadrados en zona alguna. Sin embargo, hay que advertir que existe la posibilidad de que en este último apartado, aparezcan vinos elaborados en alguna de las tres mencionadas zonas geográficas, y que, por carecer de D.O. se estudian por separado. Las zonas que se estudiarán son las siguientes:

Andalucia occidental, en la cual se citarán vinos elaborados en bodegas de tres D.O., (Jerez-Manzanilla de Sanlúcar, Montilla-Moriles y 
Condado de Huelva), que realizan unos vinos de "parecidas" caracteristicas tipológicas.

Málaga (también con D.O.), es el segundo área de estudio, que, no se ha incluido en una hipotética ( $y$ única) zona andaluza debido a que sus vinos y procedimientos de elaboración tienen una tremenda personalidad y son diferentes (no todos) a los de las tres D.O. citadas.

Zona mediterránea, este vasto territorio comprende a su vez dos subzonas con enorme tradición en este tipo de vinos: la región valenciana con dos D.O. (Alicante y Valencia), y Tarragona con tres D.O. (Tarragona, Terra Alta y Priorato).

Andalucia Occidental.-En esta zona se elaboran algunos de los vinos mejores del mundo, y su estudio se va a comenzar por la subzona más compleja y a la vez importante Jerez-Manzanilla de Sanlúcar. Posteriormente en las otras dos zonas sólo se señalarán las diferencias que existan con el modelo jerezano, para no aburrir al lector, dado que, al margen de calidades, los procedimientos de elaboración no son muy distintos. Antes de iniciar el estudio hay que decir que son vinos baratos, sin duda alguna de los que tienen mejor relación calidad-precio del mundo, pues unen a una excepcional calidad un precio muy competitivo, teniendo en cuenta sus caros procedimientos de elaboración y el enorme coste de inmovilizado que supone sus prolongadas crianzas.

Jerez-Manzanilla de Sanlúcar.-Hay pocas zonas viticolas donde se den una serie de factores tan variados (físicos y humanos), y que tengan tanta influencia en la calidad de las elaboraciones. Este quizás sea el motivo por el cual "el Jerez", en sentido genérico, sea un vino irrepetible e inimitable (a pesar de los esfuerzos de ingleses, sudafricanos, etc.). Entre los principales factores que se suelen considerar como responsables (o posibilitadores) de la calidad figuran desde el punto de vista viticola, los suelos, el clima, la planta y el cultivo, desde el punto de vista enológico, la vinificación, clasificación, y sistema de crianza y por último un aspecto muy importante y a veces olvidado, la comercialización.

El tipo de suelo es un factor tan importante que determina, veáse el Reglamento del Consejo Regulador (B.O.E. 12-5-77), la clasificación de los vinos. En Jerez hay tres tipos de suelos, las albarizas, los barros y las arenas. El Jerez Superior sólo puede proceder de pagos con suelos de albarizas, este suelo de alto contenido en caliza $\left(60^{\circ}\right)$, por un lado recoge la lluvia como una esponja formando en épocas de sequia como una costra que impide su evaporación, y por otro, debido a su color blanco (tiene un elevado albedo), refleja los rayos de sol ofreciendo una insolación extra a la planta y una maduración más homogénea. 
El clima también es un factor decisivo, con fuertes oscilaciones térmicas, precipitaciones anuales en torno a los $550 \mathrm{~mm}$, vientos del Sur y del Oeste maritimos (cargados de humedad), y una humedad relativa media del 70 por 100 , fundamental para la formación de la flor. El clima influirá hasta en el diseño de la bodega.

Las variedades de uva autorizadas son Palomino fino, Palomino de Jerez y Pedro Ximénez. También se autoriza la Moscatel para la elaboración de vinos dulces y vinos de licor. La mayoritaria es la Palomino fino que acapara casi el 95 por 100 de la totalidad del viñedo.

La vendimia y la poda se hacen con gran esmero, esta última es muy peculiar y exclusiva de la zona y hasta tal punto es importante que el Reglamento de la D.O. exige que se realice por "el sistema tradicional».

Este sistema tradicional consiste en una "poda mixta, de vara y pulgar, pero que no hay que confundirla con la poda Guyot, como ocurre muchas veces. La cepa jerezana se poda con dos brazos. En uno de ellos se deja un pulgar con una sola yema y en el otro una vara de fruto de 7 u 8 yemas. Al año siguiente se alterna..." (PEMÁN, C. 1978). Esta práctica no es gratuita y tiene como es natural su lógica, siguiendo a Pemán el pulgar se deja para tener un brote vigoroso para el año siguiente, la vara se poda en varias yemas buscando brotes algo más débiles, más fructiferos. Conviene recordar que el Reglamento permite una elevada producción y que la Palomino fino es poco fructifera en las primeras yemas. Además otra peculiaridad es que los cortes en cada brazo se hacen siempre por el mismo lado, para que en el contrario circule la savia con más facilidad. "Al lado de los cortes se le llama zona o "carrera de secos" y al lado contrario, zona o "carrera de verdes"” (PEMÁN, C. 1978).

La vendimia se realiza en la primera quincena de septiembre y es muy cuidadosa tratando de evitar fermentaciones anticipadas, para que la uva llegue en las mejores condiciones a las bodegas.

Otra peculiaridad, ya en el proceso de obtención del vino base, es como alternativa a la adición de tartárico a los mostos, la tradicional práctica del enyesado (sólo autorizada para estos vinos) para aumentar la acidez. La fermentación se realiza de forma normal y cuidadosa, «interviniendo levaduras presentes espontáneamente en el mosto; es completa, quedando sólo restos de azúcares que favorecen el posterior desarrollo de la flor» (SUÁREZ, J.A. e İ̃̃go, B. 1990).

Después de realizado un trasiego se hace una primera clasificación, por cata, para saber el futuro destino de los vinos. Los mejores se destinan para finos (o manzanillas en Sanlúcar de Barrameda), en adelante finos por abreviar, y se encabezan con alcohol vinico de la mejor calidad hasta $15-15,5^{\circ}$. 
Con el encabezado se consiguen dos objetivos, impedir el ataque de bacterias acéticas y efectuar una selección de levaduras. Dicho de otra forma, se impide que actúen otras levaduras indeseadas que refermentarian el vino, hasta que las Saccharomyces Beticus (u otras similares), desarrollen la "flor", así llamada porque aparecia en primavera.

Pasado algún tiempo, se comprueba si la clasificación ha sido correcta, en la actualidad dado el avance tecnológico de las bodegas elaboradoras no suele haber grandes sorpresas. Los "futuros finos", quedan asi durante un año o más tiempo "sobretablas", que es una especie de crianza estática en contraposición con la que tendrá lugar posteriormente. Después de una segunda clasificación en base al comportamiento de cada bota, los vinos pasarán al típico sistema de criaderas y soleras.

Según el "Reglamento", el periodo mínimo de crianza de estos vinos debe ser de tres años en vasijas de roble, pero la mayoria de las principales bodegas superan con creces en sus productos de calidad los cinco años.

«El sistema de soleras o segunda y distintiva etapa del envejecimiento de los vinos de Jerez, está compuesto por varias escalas o estadios formados por un número determinado de botas. El más antiguo se sitúa sobre el suelo, razón por el cual se denomina "solera". Sobre ésta se colocan las distintas escalas que la siguen en menos vejez, que reciben el nombre de "criaderas" y se enumeran según su orden de antigüedad respecto a aquella" (PÉREZ, L. 1991).

"Cada tipo y clase de vino posee su sistema de soleras. La solera o escala de mayor vejez suministra el vino destinado al consumo. Periódicamente, se extrae una determinada proporción del vino contenido en cada una de las botas que componen la solera, prodeciendo un vacio parcial en ellas. Esta operación se llama "saca". El vacio producido en la solera se completa con vino que procede de la escala que le sigue en vejez, o 1. ${ }^{a}$ criadera, mediante una saca a dicha escala, el vacio parcial originado en la $1 .^{a}$ criadera se repone con vino de la $2 .^{a}$ criadera, y así sucesivamente hasta la escala o criadera más joven, que se completa con vino procedente del sistema de añadas. La operación de completar el vacío originado en una escala se denomina "rocio". Esta forma de operar en el envejecimiento de los vinos hace una mezcla compleja por el número de añadas que la componen. La operación de sacas y rocíos en el soleraje recibe el nombre de "correr escalas" (PÉREZ, L. 1991).

Pero, una vez explicado perfectamente por Luis Pérez todo el proceso, ¿qué razones están detrás, o por qué se mantiene todo este complicado procedimiento?... Los fenómenos de naturaleza fisico-quimica que ocurren a lo largo del proceso son muy complejos, pero siguiendo el estudio Pé- 
Espacio y vitivinicultura. Marco territorial y apuntes tecnológicos ...

rez, Briños y Domecq (1989) desde un punto de vista práctico está justificado el sistema por varias razones, entre las que destacan:

- Elimina las oscilaciones de las distintas cosechas, ofreciendo al consumidor año tras año un vino de calidad constante.

- Posibilita la crianza biológica al incorporar a las botas nuevos nutrientes con los vinos más jóvenes.

- El trasiego del vino al "correr las escalas» activa el envejecimiento físico-químico. En efecto, el vino a través de la madera sufre una pérdida del 3 al 5 por 100 , que no tiene la misma composición que el vino que queda en la bota (por la capacidad selectiva de absorción de la madera), pero con los trasiegos se homogeneiza el vino. Además, cuando se produce el rociado se aporta de forma periódica y controlada oxigeno, que estimula el crecimiento del velo y es rápidamente consumido.

Se recomienda para estos temas, y para estudiar las cantidades de las sacas, la lectura del interesante artículo «El sistema de criaderas y soleras de los vinos y brandys de Jerez», de los tres autores citados anteriormente.

Hasta ahora no se ha mencionado (para no complicar la explicación) ningún tipo de vino, solo el fino para mantener la línea expositiva, pero ya ha llegado el momento.

En primer lugar, se debe exponer la definición que el "Reglamento" hace de los ocho tipos de vinos que se pueden elaborar con la contraetıqueta del Consejo Regulador:

- Fino: de color oro pálido, aroma punzante y delicado (recordando a la almendra), ligero, seco y poco ácido, con un contenido alcohólico del 15 al 17 por 100 vol. Obtenido mediante crianza biológica (acción de las levaduras de flor).

- Manzanilla: es un vino fino elaborado y envejecido en la localidad de Sanlúcar de Barrameda; su crianza en bodegas influidas fuertemente por la brisa marina le confiere caracteristicas peculiares. Resulta un vino más ligero que el fino y más delicado en nariz y boca. Tiene su propia denominacion de origen, Manzanilla de Sanlúcar de Barrameda, aunque no Consejo Regulador, que es el de Jerez.

- Amontillado: de color ámbar, aroma punzante (recuerda al de las avellanas), suave, seco y con un contenido alcohólico del 16 al 18 
por 100 vol. Se obtiene a partir de un vino fino sometido a un período de crianza oxidativa.

- Oloroso: de color oscuro, muy aromático, de mucho cuerpo, seco o ligeramente abocado y con un 18 a 20 por 100 vol. de alcohol. Es un vino sometido a crianza oxidativa.

- Palo cortado: tipo intermedio entre los dos anteriores, con aroma de amontillado y paladar de oloroso. Es de color oscuro y su riqueza alcohólica se sitúa entre el 18 y el 20 por 100 vol. De producción escasa, es casi una rareza.

- Raya: vino de características similares a las del oloroso, pero con aroma menos delicado. Es aún más infrecuente que el palo cortado.

- Vino dulce: procedente de uva muy madura o soleada, sometido a fermentación parcial, que se detiene mediante adición de alcohol. En este grupo se incluyen los Moscatel y Pedro Ximénez, elaborados con uvas del mismo nombre, y los Cream, parecidos a los olorosos, pero con aroma de Pedro Ximénez.

- Vino de color: obtenido mediante la fermentación de mosto fresco, al que se añade el producto resultante de la concentración de mosto por calefacción hasta el retostado o requemado de los azúcares.

Después de la larga aproximación legislativa, conviene hacer algunas matizaciones. La manzanilla es un vino excelente, sublime, y las mejores superan incluso a los mejores finos, sin embargo la manzanilla pasada está bastante alejada de la calidad del inconmensurable amontillado.

El amontillado, que para muchos autores es el mejor vino de Jerez (y para el que esto escribe también), no se suele elaborar con un fino como dice el Reglamento, sino con un vino que no ha llegado a fino, por pérdida de cualidades y se ha desviado (en la segunda clasificación) hacia otra linea de vinificación. Al futuro amontillado se le vuelve a añadir alcohol hasta unos $18^{\circ}$, quedando ya protegido de la acción de las levaduras y en el momento que la flor desaparece, "desprotegido» de la oxidación. A partir de ese momento comienza una prolongada crianza de tipo oxidativo. Este vino excepcional puede alcanzar por las evaporaciones del envejecimiento (los hay de treinta años) un grado alcohólico de 20 , y un incremento de la intensidad de color. (Como curiosidad en veinte años puede pasar «medido a $470 \mathrm{~nm}$ de 0.412 a 0.527 » según Perez Rodriguez, 1982).

Los olorosos, sin embargo (en teoria) son encabezados después de realizada la primera clasificación, hasta los $18^{\circ}$ (para inhibir toda actividad vital de la levadura), para después sufrir una crianza oxidativa muy larga. Se ha comentado que en teoria, porque algunas bodegas aprove- 
chan también vinos destinados para fino, que con muy poca crianza biológica se "han desviado", para elaborar olorosos.

Poco se va a decir de los Pedro Ximénez de Jerez, ya que, todo el mundo sabe que con los de Montilla-Moriles están entre los mejores vinos dulces del mundo. El proceso de elaboración es muy variable, y hasta tal punto que su graduación alcohólica puede ser bastante diferente de una bodega a otra. Normalmente se recoge la uva muy madura, y una vez empezada la fermentación cuando se ha alcanzado la densidad o graduación alcohólica deseada, se interrumpe añadiendo alcohol vínico de gran calidad, quedando un vino con gran cantidad de azúcares residuales pero que no resulta empalagoso debido a la enorme amplitud de sabores que posee.

Además de los moscateles, poco importantes en la zona, hay otros vinos más o menos dulces, que, aunque les encantan a los ingleses (de ahi sus nombres) tienen menos interés. Estos productos con poco arraigo en el mercado interior se elaboran mezclando diversos vinos (olorosos de baja calidad, Pedro Ximénez, etc.). Debido a su mayor éxito en el mercado exterior reciben los nombres: pale, east India, medium, cream, brown (ordenados según la proporción de azúcares residuales, en forma creciente).

Para terminar esta larga aproximación a los vinos jerezanos, se ofrecen algunos de los datos analíticos que muestra De Rosa (1987), de los cuatro principales vinos. Por cierto, que este autor italiano no cita la fuente.

Fino: alcohol $\left(15,5^{\circ}\right)$, azúcares residuales $(1,9 \mathrm{~g} / \mathrm{l})$, acidez total $(4,0 \mathrm{~g} / \mathrm{l})$ y extracto $(17,2 \mathrm{~g} / \mathrm{l})$.

Manzanilla: alcohol $\left(15,2^{\circ}\right)$, azúcares residuales $(2,3 \mathrm{~g} / \mathrm{l})$, acidez total $(4,0 \mathrm{~g} / \mathrm{l})$ y extracto $(16,4 \mathrm{~g} / \mathrm{l})$.

Amontillado: alcohol $\left(17,2^{\circ}\right)$, azúcares residuales $(2,8 \mathrm{~g} / \mathrm{l})$, acidez total $(5,1 \mathrm{~g} / \mathrm{l})$ y extracto $(22,7 \mathrm{~g} / \mathrm{l})$.

Oloroso: $\quad$ alcohol $\left(18,3^{\circ}\right)$, azúcares residuales $(4,8 \mathrm{~g} / \mathrm{l})$, acidez total $(5,3 \mathrm{~g} / \mathrm{l})$ y extracto $(28,6 \mathrm{~g} / \mathrm{l})$.

A la vista de los datos se puede comentar que, por lo menos en los últimos tiempos, el contenido alcohólico de los vinos jerezanos suele ser más elevado, sobre todo en los amontillados y olorosos.

Condado de Huelva.-Esta zona vinicola del sudoeste español, también tiene D.O., desde hace muchos años, aunque el Reglamento actual es bastante joven contando tan sólo con catorce años (B.O.E. 11-9-79). El 
Condado de Huelva es, como señalan muchos autores e incluso sus propios elaboradores, la hermana pobre de las D.O. andaluzas, y sufre una crisis de mayor magnitud que las otras. Ésta se debe, según parece entre otras razones, no sólo a la peor dotación tecnológica de sus bodegas (a pesar de ello hacen buenos vinos), sino a la orientación que tenia la zona hacia la producción de vinos a granel y aunque suene duro a "vivir un poco de las rentas" de sus poderosos vecinos, situación que ha hecho que no se organizasen mejor desde el punto de vista comercial.

Por estos y otros motivos, el Condado no sólo sufre la crisis de vinos generosos sino la que también afecta al mercado de graneles. La variedad de uva más abundante es la Zalema, que supone más del 85 por 100 de la totalidad del vidueño.

También aparecen como variedades autorizadas por el Reglamento, la Palomino o Listán (principal), Moscatel y Garrido fino. Todas ellas, por supuesto, Blancas.

Debido a la ya citada crisis, en el actual Reglamento se consideró la posibilidad de elaborar blancos jóvenes con la contraetiqueta del Consejo, aumentando de esta forma la oferta.

A esta actividad se han dedicado con notable esfuerzo numerosas bodegas y con resultados bastante dignos, consiguiendo vinos muy correctos que pueden tener un buen mercado potencial en Andalucia. En la actualidad se elaboran los siguientes tipos de vinos:

- Blanco: con una graduación alcohólica entre el 11 y el 14 por 100 vol.

- Condado Pálido: generoso de crianza biológica, con una riqueza alcohólica entre el 14 y el 17 por 100 vol.

- Condado Viejo: generoso de crianza oxidativa, con un contenido alcohólico entre el 15 y el 23 por 100 vol (pudiendo ser seco, semiseco, semidulce y dulce).

El Reglamento del Consejo Regulador es poco "generoso" con sus generosos (de cara al consumidor) estableciendo una crianza mínima de tan sólo dos años.

Aunque resulte ocioso decirlo, el Condado Pálido seria el fino de la zona, y el Condado Viejo el oloroso. El Reglamento no contempla vinos semejantes al amontillado.

Montilla-Moriles.-Esta cordobesa zona, durante mucho tiempo ha estado considerada como la productora de los "jereces de segunda" del 
pais, pero a medida que aumenta la cultura del pais está perdiendo peso la citada falacia, y los españoles están descubriendo unos vinos que van a más y que, en muchos casos, compiten en calidad con los jerezanos a un precio más ajustado. En el caso de los amontillados cordobeses, excepcionales y de los exquisitos Pedro Ximénez, los precios son tan baratos que resultan ridículos para la enorme calidad que atesoran.

Los finos de Montilla-Moriles se parecen «bastante» a los jerezanos, no en vano tienen en común el sistema de elaboración (crianza biológica, sistema de soleras, etc.), y los suelos de los viñedos (alberos en terrenos alomados).

Sin embargo también tienen notables disparidades, las variedades de uva son distintas (en esta D.O. se cultiva la Pedro Ximénez), y el clima es diferente con mayor pluviosidad pero veranos muy cálidos y secos con medias por encima de los $30^{\circ} \mathrm{C}$.

Este último aspecto tiene enorme importancia enológica pues la uva alcanza una mayor concentración de azúcares, lo que permite obtener vinos con una graduación alcohólica natural de $15-16^{\circ}$. Es decir que en la mayoria de los casos para elaborar finos no se necesita añadir alcohol, y esto tiene una doble consecuencia económica y organoléptica, aunque sea adelantar acontecimientos. Los finos de Montilla-Moriles son más baratos que los de Jerez porque en ellos se ahorra el encabezado, o parte de él. $Y$ desde el punto de vista enológico lo que mejor percibe el consumidor medio es la menor ligereza, es decir, mayor cuerpo de los vinos cordobeses en relación a los gaditanos.

Los vinos de Montilla-Moriles están reconocidos como D.O. desde hace mucho tiempo (septiembre de 1932), pero el nuevo Reglamento (para incluir, como en el Condado, los vinos blancos) es reciente (B.O.E. 27-1285).

En el Reglamento se establece que se autorizan las variedades blancas Baladi, Lairén, Moscatel, Pedro Ximénez (principal) y Torrontés. La Pedro Ximénez ocupa el 70 por 100 del viñedo.

En cuanto a los tipos de vino, como hay pocas diferencias en la Reglamentación (ni siquiera en los nombres) con los vecinos jerezanos, sólo se van a mencionar, como en el caso de la zona onubense los casos diferentes.

Aunque no tienen que ver con los vinos de postre se reseñan también como en el Condado los blancos, como ejemplo de supervivencia, la estrategia (licita pero triste) que están teniendo que utilizar estas D.O. basadas en excelentes vinos generosos, apuntándose a la moda de los blancos afrutados y fragantes, y que contrasta con la materia prima de la que 
parten, que no suele ser precisamente, muy aromáticas. La próxima será Málaga.

Ruedo:

generoso sin crianza, generalmente pálido, ligero y seco, con un contenido alcohólico mínimo del 14 por 100 vol. Para que este vino pueda ser comercializado bajo la denominación de origen debe ir mezclado con al menos un 10 por 100 de vinos de crianza amparados por la D.O. Montilla-Moriles. Se puede comercializar tan solo en territorio nacional en envases de capacidad no inferior a cinco litros.

Pedro Ximé- vino dulce natural, de color rubi oscuro, obtenido a nez: partir del mosto de uva soleada de la variedad Pedro Ximénez que se somete a fermentación alcohólica parcial. Tiene un contenido en azúcares superior a 272 gramos por litro.

Blanco sin vino jóven, muy pálido, de aroma frutal y entre un 10 envejecimiento: y un 12 por 100 vol. de alcohol. Se debe elaborar mediante sistemas que permitan mantener una temperatura adecuada durante la fermentación y aplicando tecnologias que garanticen su conservación, fragancia, frutuosidad y demás características naturales. Se comercializa en envases de capacidad máxima de 0,75 litros.

Blanco con vino que por sus especiales caracteristicas y las vaenvejecimiento: riedades de que procede alcanza una graduación natural minima del 13 por 100 vol. y que se somete a envejecimiento. Un año en envases de roble de capacidad inferior a 1.000 litros.

Aparte del ruedo, vino que se suele tomar bastante en las tabernas de las poblaciones cordobesas (y que tiene un precio «que da risa»), la mayor diferencia con Jerez en tipo de vinos está en los dulces. En MontillaMoriles se privilegia el Pedro Ximénez, no les falta razón, y según el reglamento, no puede por ejemplo, existir un Moscatel dulce con la contraetiqueta del Consejo Regulador. En Montilla Moriles se permite el asoleo de la uva Pedro Ximénez, para obtener ese excepcional vino dulce, que es un auténtico lujo... al alcance de todos.

Una etiqueta, otra falacia más, que tienen colgada los vinos montillanos es la de su alta graduación, pero hay que decir que el Reglamento de Montilla-Moriles tiene unos limites legales de alcohol incluso más ba- 
jos para algunos de sus vinos acogidos que los de Jerez, aunque, en la práctica, se debe señalar que las grandes marcas de las dos D.O. tienen unas proporciones similares.

¿Qué diferencias se tiene con los sistemas de soleras respecto a la crianza estática? Aunque ya se comentó en Jerez, conviene para completar la explicación insistir en este importantisimo aspecto, ya que los consumidores piensan que se hace exclusivamente para que el vino tenga una calidad constante año tras año.

Siguiendo el espléndido trabajo de Díaz Alonso y López Alejandre, con levadura en flor y sin el sistema de soleras, se iría produciendo un debilitamiento del velo, una merma continua por evaporación a través de las paredes, y a la postre una desaparición del velo con concentración de grado alcohólico (la molécula de agua de menor tamaño atraviesa mejor los poros de la madera), y un paso a las condiciones de envejecimiento oxidativo,....

«Si por el contrario, sometemos el vino al sistema de criaderas y soleras, el vino se nos mantiene en un estado de reducción característico, de un color pálido y unas particularidades que to hacen hoy el más apetecido y demandado de nuestros vinos y que, sin embargo, es el hermano pequeño de los amontillados. Su nombre es fino..." (DIAZ, A. y LOPEZ, M. 1989). Se acaba esta sintesis de los vinos generosos cordobeses con algunos datos analíticos, extraídos del trabajo de los autores anteriormente mencionados.

Fino: alcohol $\left(15,5^{\circ}\right), \mathrm{pH}(3-3,3)$, acidez total $(3,8-6,1 \mathrm{~g} / \mathrm{l})$, azúcares reductores $(0,75-1,4 \mathrm{~g} / \mathrm{l})$ y extracto seco $(15-$ $20 \mathrm{~g} / \mathrm{l})$.

Amontillado: alcohol $\left(16-18^{\circ}\right), \mathrm{pH}(2,7-3,0)$, acidez total $(3,8-6,1 \mathrm{~g} / \mathrm{l})$, azúcares reductores $(1,3-2,5 \mathrm{~g} / \mathrm{l})$ y extracto seco (17$22 \mathrm{~g} / \mathrm{l})$.

Oloroso: $\quad$ alcohol $\left(18-20^{\circ}\right)$, acidez total $(3,8-6,1 \mathrm{~g} / \mathrm{l})$, azúcares reductores $(2-4 \mathrm{~g} / \mathrm{l})$ y extracto seco $(18-25 \mathrm{~g} / \mathrm{l})$.

Pedro Ximénez: alcohol $\left(8-15^{\circ}\right)$, acidez total $(3,8-6,1 \mathrm{~g} / \mathrm{l})$, azúcares reductores (Más de $150 \mathrm{~g} / \mathrm{l}$ ) y extracto seco (Más de 170 $g / l)$.

Málaga.-El reglamento en vigor es relativamente reciente (B.O.E. 2112-76), aunque son vinos reconocidos como D.O. (los segundos) desde septiembre de 1932. Se está intentando modificar el Reglamento actual con objeto de diversificar más el abanico de la oferta, y de acoger ela- 
boraciones de la zona similares a las de los «finos", "olorosos" etc., y como no, seguro que también aparecerán los «blancos jóvenes».

Las variedades autorizadas son blancas, las conocidas Pedro Ximénez (aqui Pero Ximén) y Moscatel. La primera es más abundante en el interior y la segunda tiene mayor vocación costera.

En este apartado se van a tratar esos clásicos vinos que desde tiempo inmemorial le han dado un merecido prestigio internacional a la zona. Como todo el mundo sabe son vinos encabezados, de crianza, que se elaboran con mezclas de vinos tipo, o mejor dicho vinos base. Para la clasificación de estos vinos se utilizan diversos criterios.

Según el contenido en azúcares pueden ser como cualquier otro vino: dulces, semidulces, semisecos, abocados y secos.

Según el color pueden ser: blancos, dorados, rojo-dorados, oscuros y negros.

Según el origen de los mostos: Lágrima, Pedro Ximénez y Moscatel.

También se admiten otras expresiones como ya se verá más adelante.

Estos vinos se comercializan después de una crianza mínima de dos años, y se puede seguir tanto el procedimiento de criaderas y soleras como el de añadas.

Su procedimiento de fabricación es bastante complejo y ha estado rodeado de un cierto halo de secretismo, que, como señala Luis de la Maza (Presidente del Consejo Regulador de la D.O.), en nada ha beneficiado a los buenos profesionales de estos vinos y que ha permitido los plagios e imitaciones.

Resulta dificil, por lo tanto, explicar la elaboración de estos vinos de mezcla, ya que, cada bodega lo hace de la manera que estima más oportuna, no obstante en base a la excelente monografia de Félix Valencia, y en menor medida, al estudio de Adolfo Vasserot sobre vinos de Málaga, se pueden extraer algunas ideas de carácter general y jugosas conclusiones.

Dentro de los vinos base se encuentran, el vino maestro, el arrope, el Color, el vino de licor y el vino borracho. El vino seco y el Málaga blanco Dulce pueden ser tanto vinos base como vinos Málaga del Comercio.

El vino tierno: resulta sorprendente, que el Reglamento de la D.O. no incluya este vino tradicional en la elaboración del vino de Málaga. Existe una fuerte controversia bibliográfica sobre este vino base, pero en el Reglamento $4252 / 88$ de la CEE ha sido identificado con el "mosto parcialmente fermentado procedente de uva sobremadurada en la planta o soleada", por lo cual ya no puede ser una simple mistela de uva soleada. 
Además, "de acuerdo con los Reglamentos Comunitarios ha de proceder de un mosto de al menos $272 \mathrm{~g} / \mathrm{l}$ de azúcar, tener al menos 1 por $100 \mathrm{vol}$. de alcohol de fermentación natural y también un mínimo de 8 por 100 vol. de alcohol tanto de fermentación como añadido" (VALENCIA, F. 1990).

Vino maestro: para muchos autores antiguos es una mistela, el Reglamento del Consejo lo define como vino procedente de fermentación muy incompleta porque antes de que comience la fermentación se encabeza el mosto con 7 por 100 vol. de alcohol; la fermentación muy lenta se paraliza cuando llega a $15-16^{\circ}$, quedando $160-200 \mathrm{~g} / \mathrm{l}$ de azúcares. El mosto inicial debe tener entre 16,5 y $20,5^{\circ}$ Bé. Resulta al menos sorprendente el calificativo de fermentación «muy incompleta».

Arrope: es el producto resultante de la concentración o deshidratación de los mostos empleando el fuego directo o el baño María. «En el primer caso se utiliza una caldera de cobre estañado o acero inoxidable, donde se sitúa el mosto. La ebullición, muy activa al principio, se va moderando poco a poco. Es preciso agitar continuamente para evitar el requemado y al final el volumen se reduce a un tercio del primitivo. En el segundo caso, el mosto se calienta garcias a un serpentín por donde circula el agua" (VASSEROT, A. 1978).

Color o pantomima: arrope quemado hasta reducir su volumen a la mitad aproximadamente, y apagado. Según Garijo, citado por Valencia, el arrope se pasa a una calderilla, y se concentra hasta la mitad del volumen inicial, no adicionando ni agua ni vino que reducirian por dilución el poder colorante del color obtenido. El inconveniente del color es que amarga bastante.

Vino de licor: es una mezcla de arrope, de Color y de aguardiente.

Vino borracho: «mezcla a partes iguales, generalmente de vino y alcohol de $96-97^{\circ}$ centesimales para que cuando sea preciso, por su crianza y elaboración, encabezar un vino éste reciba el impacto del alcohol muy mitigado y el vino no se queme". (Gariso 1985). Su finalidad es evitar el enturbiamiento que se produce al mezclar vino nuevo y alcohol de alto grado.

Vino Málaga seco: se obtiene por fermentación hasta sequedad de mosto de uva Pero Ximén, vidueño e incluso Moscatel, evidentemente sin asolear. Su grado alcohólico es variado, según el Dpto. de Investigación de Larios puede oscilar entre los 11 y los $16,8^{\circ}$ (media de $13,2^{\circ}$ ).

Vino de Málaga blanco Dulce: procede de uvas, bien maduras y asoleadas para lograr mosto de hasta $28^{\circ}$ Bé., empleando solamente mostos de yema, cuya fermentación es muy lenta e incompleta. Pero según Valencia (1990), en la actualidad puede bastar que el mosto pase de 16,0 
Bé. Este vino constituye la base de todos los vinos de Málaga del comercio, excepto, lógicamente, de los secos y pajarete.

Una vez presentados los vinos base, hay que pasar a los que están al alcance de los consumidores, es decir, los llamados vinos Málaga del comercio.

Vino Málaga Pajarete: es un vino poco dulce $\left(2.3^{\circ}\right.$ Bé.), de color ámbar - ámbar oscuro que no precisa mucha crianza. Según análisis de Larios S.A. este vino presenta entre otros los siguientes datos: alcohol $(17,13$ por 100 vol.), $\mathrm{pH}(3,56)$, acidez total $(3,20 \mathrm{~g} / \mathrm{l})$, azúcares $(98,8 \mathrm{~g} / \mathrm{l})$, extracto seco $(124,5 \mathrm{~g} / \mathrm{l})$.

Málaga Lágrima: es el Málaga dulce, en cuya elaboración sólo se ha empleado el mosto que sin presión mecánica alguna, una vez pisada la uva, fluye de ella. Esto quiere decir que en la actualidad no se elabora ningún vino de Lágrima conforme a la legislación, no obstante, algunas bodegas llaman asi a su producto más selecto. Además la uva debe solearse en la cepa o fuera de ella, pues el azúcar de este vino solo debe ser el natural, debido a la fermentación parcial. (No se puede añadir arrope, tierno, etc.).

Málaga Dulce Color: es el más conocido de los vinos de Málaga, y en su elaboración parece que no hay acuerdo. El procedimiento genuino malagueño consiste en añadir arrope 2-3 por 100, al mosto, que fermentará lentamente. Este vino se envejece después de largo tiempo. Otros autores plantean otras alternativas. El Málaga Dulce Negro es igual pero con una mayor proporción de arrope (12-15 por 100). Los datos de este vino: alcohol (14,3-15,6 por $100 \mathrm{vol}.), \mathrm{pH}(3,6)$, acidez total $(4-5,2 \mathrm{~g} / \mathrm{l})$, azucares $(145-200 \mathrm{~g} / \mathrm{l})$, extracto seco $(170-230 \mathrm{~g} / \mathrm{l})$.

Málaga Dulce Pero Ximén: es el vino que procede exclusivamente de uvas de esta variedad. Se exigirá solo el 85 por 100 del carácter varietal. Después de asolear la uva unos dias se obtienen mostos de $22^{\circ}$ Bé., y una vez en las tinajas se puede añadir de un 2 a un 3 por 100 de arrope (de la variedad), y se detiene la fermentación por adición de alcohol. Otros autores plantean que una vez fermentado se le añade un 4-6 por ciento de tierno o maestro para aumentar la dulzura. Del análisis dirigido por Valencia se ofrecen los datos siguientes: alcohol (14,7-15,6 por 100 vol.), $\mathrm{pH}(3,4-3,83)$, acidez total $(3,13-3,68 \mathrm{~g} / \mathrm{I})$, azúcares $(133,6-223,0 \mathrm{~g} / \mathrm{l})$, extracto seco $(158,1-251,5 \mathrm{~g} / \mathrm{l})$.

Málaga Dulce Moscatel: el procedente exclusivamente de la uva Moscatel. Se admitirá un $85 \%$ o más. Vasserot ofrece entre otros datos: alcohol $(15,81 \%$ vol.), acidez total $(4,72 \mathrm{~g} / \mathrm{l})$, azúcares $(213,1 \mathrm{~g} / \mathrm{l})$, extracto $\operatorname{seco}(41,3 \mathrm{~g} / \mathrm{l})$. 
Zona Mediterránea.-Ya se han mencionado las dos zonas que compondrán este apartado, pero tanto en la región valenciana como en Cataluña, los vinos de licor ya no tendrán el protagonismo que ostentaban en las D.O. de Andalucia, aunque en algunos rincones de estas dos regiones todavía se sigue manteniendo una fuerte tradición en este tipo de elaboraciones, como los moscateles de todo levante y la zona en torno a Gandesa en la D.O. Terra Alta. Dada la poca incidencia que tienen no se han incluido en este apartado, a pesar de tener D.O., los vinos de licor de Jumilla y Almansa.

Región valenciana.-La primera parte corresponde a vinos de Alicante, que tienen D.O. reconocida desde 1932 aunque el Reglamento vigente es de hace poco tiempo (B.O.E. 7-7-87).

El clima de esta zona es mediterráneo seco con precipitaciones anuales aproximadas de 300 a $500 \mathrm{~mm}$. Se debe destacar que en aquellas zonas que no alcanzan los $400 \mathrm{~mm}$ tienen permitido el riego en invierno.

Dentro de la zona de producción hay una subzona Marina Alta de vinos licorosos moscatel. Ésta es más húmeda y alomada que el resto de la D.O.

Las variedades de vid autorizadas son las tintas Monastrell, Garnacha y Bobal; y las blancas Merseguera, Moscatel romano y Verdil.

En cuanto a los vinos objeto de este trabajo, el Reglamento establece los siguientes:

Vino de licor rosado: con un 15 por 100 vol. de graduación alcohólica mínima.

Vino de licor tinto: minimo 15 por 100 vol. de alcohol.

Vino de Licor Moscatel Alicante: minimo 15 por 100 vol. de alcohol.

Fondillón: con riqueza alcohólica minima del 16 por 100 vol.

Los vinos sometidos a crianza deben envejecer durante al menos dos años, de los cuales al menos uno deben permanecer en barricas de madera. El Fondillón se envejece mediante el sistema de soleras, durante un período mínimo de ocho años.

Las ventas de vinos de crianza, incluido el Fondillón, no deben superar en cada campaña el 40 por 100 de las existencias en bodega al inicio de dicha campaña.

Los más importantes desde el punto de vista económico son los moscateles, que frecuentemente se venden a granel a zonas próximas a los mercados de consumo donde se embotella. 
El Fondillón, que como todo el mundo sabe se elabora a partir de la variedad Monastrell, es uno de los vinos más antiguos de España, algunos escritores ya lo citan en la época de Felipe II. Dentro de las características del Fondillón, aparte de ser un vino caro y muy escaso, se debe destacar su larguisima crianza, los elaboradores normalmente lo dejan de diez a doce años en barrica de roble y otro tanto en botella. Es un vino excepcional que no debe perderse, con unas peculiares caracteristicas organolépticas: color caoba, con aromas de frutos secos, madera, etc. En boca es vigoroso pero suave (dada su larga crianza), con buena estructura, y larga persistencia. Vía retronasal potente. No obstante se ve perjudicado por su, lógicamente, alto precio.

La D.O. Valencia, también de reconocimiento antiguo como las anteriores zonas, tiene un Reglamento muy reciente (B.O.E. 3-7-87). Esta D.O. está dividida en cuatro subzonas Alto Turia, Clariano y las dos que aquí más interesan, Valentino y Moscatel de Valencia (con ocho municipios comunes con Valentino).

Las variedades autorizadas son, para Valentino: Merseguera, Planta Fina, Pedro Ximénez y Malvasía, y las tintas Garnacha y Garnacha Tintorera.

En Valentino se elaboran, además de blancos, rosados y tintos (en los tres casos secos, semisecos y dulces), vinos de licor: con más del 15 por 100 vol. de alcohol y vinos rancios: con graduación alcohólica minima del 15 por 100 vol.

En la subzona de Moscatel no hace falta decir cual es la variedad autorizada, y si al final se dice, es por el "apellido», Moscatel romano. Se elaboran en la zona dos tipos de vino: Moscatel dulce, con graduación alcohólica minima del 14 por 100 vol., y vino de licor Moscatel de Valencia, con al menos 15 por 100 vol. de alcohol.

Cataluña.-Es una región en la que abundan este tipo de elaboraciones, y desde antaño casi todas las bodegas dejaban alguna bota dedicada a vino rancio en algún rincón apartado, de ahí el conocido nombre de bota del recò. Pero además de este sistema de enranciamiento, «en algunas comarcas también era costumbre exponer estos vinos rancios previamente encabezados con alcohol de vino hasta 18 o $20^{\circ}$, a la acción del sol y de las inclemencias del tiempo" (Torres, M. 1982). Si hay una zona catalana preponderante en vinos de postre, ésta es sin lugar a dudas la provincia de Tarragona que acoge tres D.O. en las que se dan este tipo de elaboraciones: Tarragona, Terra Alta y Priorato.

Tarragona es una zona de enorme tradición viticola, destinándose ya los vinos de la antigua Tarraco a la Roma imperial, y según cuentan "a 
mediados del siglo xII el monasterio de Santes Creus, en el norte del Camp de Tarragona, era ya un foco vitivinicola muy importante» (FEIJOO, I. 1987). Tiene reconocida D.O. desde 1932 y el actual Reglamento es de hace quince años (B.O.E. 22-12-76).

La D.O. Tarragona cuenta con dos subzonas Tarragona Campo y Falset siendo esta última la que más interesa para este trabajo, por elaborarse en ella dos vinos de licor. Las variedades de uva del Falset son tintas y solamente dos, la Garnacha y la Cariñena. Con ellas se elaboran los dos vinos que contempla el Reglamento de la D.O.:

Tarragona clásico: vino licoroso con un envejecimiento mínimo de dos años en envase de roble; su contenido alcohólico mínimo es de $13^{\circ}$. Rancio: envejecido durante al menos unos cuatro años en envases de madera y de vidrio, con un mínimo el 14 por 100 vol. de alcohol.

La Terra Alta es una zona situada al oeste de la provincia, tiene D.O. desde 1972 (B.O.E. 12 de diciembre). Las variedades de uva autorizadas son las blancas Macabeo y Garnacha Blanca y las tintas Cariñena, Garnacha Tinta y Garnacha Peluda.

Además de elaborarse blancos, tintos y rosados, también aparecen aqui los vinos rancios, que deben tener un contenido de más del 15 por 100 vol. de alcohol. Para los vinos rancios secos, el período de crianza mínimo es de cinco años en envases de roble; los rancios abocados y dulces tienen un periodo de crianza mínimo de dos años en envases de roble. Pueden partir tanto de variedades blancas como tintas, y está permitida en su elaboración la adición de alcohol.

El Priorato es la zona vitivinicola más importante de la provincia de Tarragona, no en extensión (es la más pequeña), sino por la calidad de sus productos (algunos de sus tintos son extraordinarios). Su D.O. también tiene reconocimiento desde el año 1932 y el reglamento vigente apareció en el B.O.E. de 26-6-75, siendo sus variedades de uva autorizadas las siguientes:

Blancas: Garnacha Blanca, Macabeo y Pedro Ximénez. Tintas: Garnacha, Garnacha Peluda y Cariñena. La uva Garnacha es considerada variedad principal. Además de blancos, rosados y tintos, produce generosos y rancios. Generoso: del 14 al 18 por 100 vol. de alcohol. Rancio: con un contenido alcohólico entre el 14 y el 20 por 100 vol.

Los rancios deben envejecer durante al menos cuatro años, y en su elaboración se fuerza la oxidación exponiendo los vinos en barriles de roble a la intemperie, con fuertes oscilaciones de temperatura. Los tintos pierden su color característico y los blancos se oscurecen y se forman productos volátiles que les dan el aroma característico. 
Los generosos que pueden ser semidulces o dulces y pueden tener en su elaboración adición de alcohol siempre que hayan adquirido $8^{\circ}$ de alcohol natural.

\section{OTROS VINOS DE LICOR}

En este apartado final se van a, por lo menos, nombrar unos cuantos vinos de postre que a pesar de no estar acogidos a denominación de origen poseen una indudable calidad y prestigio. Su localización en el territorio español es muy dispar y pueden estar tan alejados como los Malvasías canarios de las catalanas Garnatxas.

Es obligado comenzar con los vinos del Aljarafe que tienen unas características similares a los de Jerez pero que no están avalados por ninguna denominación de origen. No merece la pena detenerse en ellos, no porque no tengan calidad, que la tienen, sino porque son de similar elaboración que sus famosos vecinos.

Tampoco debe olvidarse la zona de Rueda que tiene ancestrales vinos de crianza biológica y oxidativa amparados con D.O., aunque estén en franca decadencia. El Reglamento así los define:

Pálido Rueda: generoso de crianza en flor, pálido ligero y seco, encabezado con alcohol vínico hasta que alcanza una graduación alcohólica mínima del 14 por 100 vol.

Dorado Rueda: generoso de crianza oxidativa, de color caoba y aroma intenso, encabezado con alcohol vínico hasta que alcanza una riqueza alcohólica minima del 15 por 100 vol.

En la crianza de vinos generosos, el periodo mínimo de envejecimiento es de cuatro años, los tres últimos en envase de roble de capacidad inferior a los 1.000 litros en el caso del Pálido Rueda, y los dos últimos en envases de iguales características, en el caso de los Dorado Rueda.

También existen en la provincia de Valladolid, otros casos de vinos de crianza oxidativa y $\sin$ D.O. que oxidan el vino con damajuanas expuestas al sol y a los contrastes de temperatura. Práctica antigua también corriente en la zona de Rueda.

Los Moscateles se dan por todo el pais, se trata como ya se ha comentado de vinos a los que se les ha interrumpido la fermentación por adición de alcohol y que tienen por lo tanto una elevada proporción de 
Espacio y vitivinicultura. Marco territorial y apuntes tecnológicos ...

azúcares residuales. En su elaboración se utiliza normalmente uva fresca, es decir sin asolear.

A pesar de partir de variedades de Moscatel, hay notables diferencias entre ellos. y se elaboran incluso de esa parte tan atípica en vinos de postre como el interior penínsular (salvo Montilla-Moriles), por ejemplo en algunas zonas de Aragón como Cariñena y Campo de Borja, y en Navarra.

En la franja costera y de sur a norte se pueden citar los moscateles de: Chipiona (en Cádiz), en el Aljarafe sevillano, en Murcia, en zonas de Alicante y Valencia no acogidas a D.O. y dentro de esta región en una provincia tan poco vitivinicola como Castellón ("famosa" por sus hibridos productores directos) en la zona de Benicasín. En Cataluña hay bastantes zonas productoras, sobre todo en el Penedés, en la cual la alta tecnología de muchas bodegas permite la elaboración de una enorme variedad de vinos dulces, entre los cuales no falta el Moscatel. Merece la pena añadir que en Baleares y en Cataluña se elaboran vinos "secos normales" de uva Moscatel de gran calidad. También conviene destacar que en casi toda España, y sobre todo en Levante, se venden mistelas embotelladas de uva moscatel etiquetadas como «vino de moscatel». Deberia abandonarse esta práctica que confunde al consumidor ya que en el caso de la mistela no existe fermentación alguna sino una mezcla de mosto y alcohol.

Otros vinos ilustres son los Malvasias de la comarca vitivinicola La Geria, en la isla de Lanzarote. Son buenos vinos pero caros dada la poca rentabilidad que ofrecen sus épicas condiciones de cultivo por todos conocidas. Sin salir del archipiélago, en la comarca vitivinicola de Fuencaliente, en la isla de La Palma se elaboran también, aunque son menos famosos, buenos Malvasias de postre. Esta variedad también se utiliza en estas islas (como en la zona de Toro) para blancos jóvenes de mucho menos interés.

En Jumilla y con D.O. algunas bodegas ofrecen vinos duices naturales (12 al 15 por 100 vol. alcohol), que se pueden encabezar. La variedad es la tinta Monastrell. En la provincia de Badajoz, sobre todo en Almendralejo (Tierra de Barros) también hay vinos generosos, pero por desgracia (salvo honrosas excepciones) no abundan ni las calidades ni los embotellados.

Y por último, destacar que además de los casos puntuales de vinos rancios que abundan por el litoral mediterráneo y en algún que otro lugar como Cebreros, existe un vino muy famoso que incomprensiblemente está fuera de la D.O., a la cual indudablemente prestigiaria, ese vino es la Garnatxa del Ampurdán. 
La Garnatxa se da en el ámbito geográfico de la D.O. Ampurdán-Costa Brava, que tiene en la uva Garnacha a su variedad principal. Las Garnatxas del Ampurdán son vinos de postre de gran calidad, con un contenido alcohólico entre 14 y 16 por 100 vol. y 5-6 Bé., que se elaboran por adición de alcohol vínico al mosto en fermentación. Suelen tener crianza en madera (12 meses o más) y los llamados reservas además de estar un tiempo en depósito pueden llegar a los cuatro años de crianza en barrica de roble y otro tiempo más breve en botella.

Otro caso similar es el de otro vino de notable calidad pero sin D.O. la Malvasia de Sitjes, un vino raro en la actualidad pero famoso en otro tiempo y con un viñedo en franca recesión por la presión del uso turístico.

\section{EL VINO DE LICOR, UN INCIERTO FUTURO}

No se pretende con este epílogo ni un apartado de conclusiones ni un alegato apologético de estos vinos, pero si aportar algunas reflexiones o al menos suscitar la polémica por la injusta y problemática situación que atraviesan los vinos que quizás tengan una mayor vinculación con el medio geográfico.

Algunos autores plantean para explicar su precaria situación que los gustos de los consumidores pueden haber cambiado, el sabor dulce no gusta, o como dicen algunos en lenguaje coloquial "ya no se lleva». Otros cargan las tintas en la moda "light», ya que son vinos de elevada graduación alcohólica (entre los 15 y 19 por 100 vol.).

Pero las anteriores argumentaciones tienen poca consistencia, pues por un lado los vinos de licor conforman un abanico gustativo excepcionalmente amplio (desde los secos finos hasta los exquisitos dulzores de los Pedro Ximénez), y por otra parte si se considera el aumento de los sintéticos (por sus aromas) y dulzones licores «light" (más azucarados y alcohólicos que los vinos) también se invalida la segunda hipótesis. Y esta última argumentación se derrumba totalmente si se observa el incremento del consumo de pacharanes, aguardientes, whiskys, etc.

No obstante, el mayor problema que tienen los vinos licorosos y generosos es el absoluto desconocimiento que de ellos tienen los potenciales consumidores, y este problema tiene dificil solución ya que no son vinos rentables para los bodegueros. Debido al alto coste de inmovilización que supone su elaboración y que no se puede repercutir totalmente en el precio, para qué incrementar aún más éste con la publicidad si no son productos de moda. 
A pesar del sombrio panorama, hay razones objetivas que hacen suponer que unos productos genuinos tan vinculados con el territorio y la tradición pueden tener mejores perspectivas que las de ese incierto futuro que hoy les amenaza. Para ello tienen que hacer un esfuerzo tanto las bodegas elaboradoras como la restauración. Si en Portugal ofrecen en muchos lugares al principio de la comida un Oporto blanco o seco y al final de la misma un Oporto, Madeira o Moscatel de Setúbal (todos ellos espléndidos), ¿por qué no se hace lo mismo en España con los vinos de licor del pais?

Su rica y larga historia, su uso en la cocina y su enorme versatilidad, se pueden tomar en cualquier momento del dia, aperitivo, almuerzo, postre, entre horas, etc., hacen suponer que cuando se conozcan suficientemente cambiará su situación de forma radical.

Por otra parte, no se debe olvidar su calidad, gracias a ella siguen persistiendo, ya que las mismas bodegas reconocen que los siguen elaborando "solo por prestigio" aunque los tengan que "subvencionar" con otros productos más rentables, brandy, ginebra, licores, etc.

Esta calidad y su indudable personalidad deben ser las mejores armas para que puedan llegar a más consumidores y que dejen por fin, de ser patrimonio exclusivo de unos pocos privilegiados que los conocen, que los conocemos,... el resto de los españoles también se lo merece.

\section{BIBLIOGRAFIA}

Bibulus (1986): Vinos del Mundo. Barcelona, Elfos, 211 págs.

B.O.E. (1972): Reglamento de la Ley 25/1.970, "Estatuto de la Viña, del Vino y de los Alcoholes". B.O.E. n. ${ }^{\circ} 87,11$ abril 1972, págs, 6.390-6.424.

C.E.E. (1988): Reglamento $n{ }^{\circ} 4.252 / 88$. Relativo a la elaboración y a la comercialización de los vinos de licor producidos en la Comunidad. D.O. de las Comunidades Europeas n. L 373, 21 diciembre 1988. N..$^{\circ}$ L 373/59-65.

- (1987): Reglamento $\mathrm{n}^{\circ}$ 822/87. Por el que se establece la organización común del mercado vitivinicola, 53 págs.

CLUB DE GOURMETS (1992): Guia de vinos Gourmets 1992. Madrid, 736 págs.

DE RosA, T. (1987): Tecnologia dei vini liquorosi e da dessert. Brescia, Edizioni AEB, 202 págs.

Diaz, A. L., y Lopez, M. M. (1989): Los vinos de Córdoba. Córdoba, Caja Provincial de Ahorros de Córdoba, 198 págs.

EQUIPO DE TRABAJO G.R.E.L.A. (1987): El sector vitivinicola de Castilla y León y la C.E.E. Valladolid, Consejería de Economía y Hacienda, Junta de Castilla y León, 443 págs.

FElJoo, I. (1987): Vinos y Cavas de España. Amparados por Denominación de Origen. Barcelona, Edicomunicación, S.A., 391 págs.

YRAVEDRA, G. (1983): “Liaison qualité-terroir", en Bulletin de l'O.I.V. Paris, págs. 854-862.

Johnson, H. (1979): El Vino. Atlas Mundial de Vinos y Licores. Barcelona, Blume, 292 págs. 
MARTinez, M. (1988): «Porto, el gran aristócrata», en Viña y Vino n. ${ }^{\circ} 51$. Madrid, págs. 12-26.

M.A.P.A. (1989): Guia de productos españoles con Denominaciones de Origen, Genéricas y Especificas. Madrid, Secretaría General Técnica del M.A.P.A., 316 págs.

- (1989): Colección de fichas técnicas de las Denominaciones de Origen de los vinos de España. Madrid, Subdirección General del I.N.D.O. (M.A.P.A.), Documento interno.

Noguera, J., y Seno, F.J. (1973): Los grandes vinos. Ensayo sistemático para el estudio de los vinos españoles. Alicante, Ed. Biblioteca Alicantina, 179 págs.

Peñin, J. (1982): Manual de Vinos Españoles. Madrid, Penthalon, 303 págs.

PeMÁn, C. (1978): "La poda de la vid en Jerez". Madrid. Boletín A.N.I.A., págs. 367-376.

Pérez, L. (1991): "La crianza del vino de Jerez", en Vitivinicultura n. 9 (septiembre). Madrid, págs. 19-22.

Pérez, L.; Briños, J. S., y Domeca, B. (1989): «El sistema de criaderas y soleras de los vinos y brandys de Jerez", en Viña y Vino n. 53 (Extra 1989). Madrid, págs. 76-80.

Pernaud, E. (1989): Enologia práctica. Conocimiento y elaboración del vino. Madrid, MundiPrensa, 402 págs.

Ribereau-Gayon, J. et alii (1976): “Sciencies et techniques du vin. Traité d'oenologie», Tome 3. Vinifications. Transformations du vins. París, Dunod, 656 págs.

SuArez, J. A., e lîigo, B. (1990): Microbiologia enológica. Fundamentos de vinificación. Madrid, Mundi-Prensa, 539 págs.

Torres, M. (1982): Manual de los vinos de Cataluña. Madrid, Penthalon, 303 págs.

Torres, P. (1991): "Les vins de liqueur. Rapport de synthèse", en Vins de liqueur. Viticulture, 71 Assemblée Generale de la Office International de la Vigne et du Vin. Paris. Documento interno de la O.I.V.

VAlencia, F. (1990): Monografía sobre los vinos de Málaga. Málaga, Larios S.A., 391 págs.

VASSERot, A. (1978): El vino de Málaga. Málaga, Grupo de Ordenación Comercial Exterior, 174 págs.

V.V.A.A. (1982): Guia de vinos. Madrid, Planeta.

VOGt, E. (1971): La fabricación de vinos. Zaragoza, Acribia, 292 págs. 